Harel, Simon, Laurent Lussier et Joël Thibert, 2015. Le Quartier des spectacles et le chantier de l'imaginaire montréalais, Québec : Presses de l’Université Laval

\title{
Guillaume Ethier
}

URL : http://journals.openedition.org/eue/1382

ISSN : 1916-4645

Éditeur

Institut national de Recherche scientifique Urbanisation Culture et Société

Référence électronique

Guillaume Ethier, « Harel, Simon, Laurent Lussier et Joël Thibert, 2015. Le Quartier des spectacles et le chantier de l'imaginaire montréalais, Québec : Presses de l'Université Laval », Environnement Urbain / Urban Environment [En ligne], Volume 10 | 2016, mis en ligne le 05 octobre 2016, consulté le 01 mai 2019. URL : http://journals.openedition.org/eue/1382

Ce document a été généré automatiquement le 1 mai 2019.

(C) Institut National de Recherche Scientifique Centre Urbanisation Culture et Société 


\title{
Harel, Simon, Laurent Lussier et Joël Thibert, 2015. Le Quartier des spectacles et le chantier de l'imaginaire montréalais, Québec : Presses de l'Université Laval
}

\author{
Guillaume Ethier
}

1 Premier ouvrage consacré entièrement au plus important projet d'urbanisme culturel à Montréal, Le Quartier des spectacles et le chantier de l'imaginaire se présente comme une vaste chambre d'écho où se mêlent les points de vue interdisciplinaires quant au rôle que peut - et devrait - jouer le design urbain dans la redéfinition identitaire d'un secteur de ville. C'est d'ailleurs en vertu de cet assemblage hétéroclite que le livre est à l'image du Quartier des spectacles. Comme l'entendent en effet une bonne partie de ses auteur-e-s, tout projet urbain d'une telle envergure (secteur d'intervention de $1 \mathrm{~km}$ carré) ne peut être pensé comme un objet fini, exempt de toutes les aspérités et lignes de tension qui, de lutte en lutte, le façonne. Ce qui vaut pour le Quartier des spectacles vaut aussi pour le livre, car c'est cette diversité de regards qui en constitue la principale réussite. Si le contenu des chapitres varie considérablement, et que ses auteur-e-s adoptent des trajectoires narratives fort différentes, ils nous exposent tous à une modalité différente de la rencontre entre le Quartier des spectacles et le territoire qu'il cherche à repositionner dans l'imaginaire urbain montréalais.

Le Quartier des spectacles de Montréal est une initiative multidimensionnelle à placer dans la lignée des projets de régénération urbaine par la culture, un type de stratégie en vogue depuis les années 1980. S'inscrivant plus précisément à l'adresse du «place branding » (Kalandides, Kavaratzis, Lucarelli, \& Olof Berg, 2011), c'est-à-dire s'appuyant sur la promotion de l'ADN d'un lieu, le Quartier des spectacles propose de prolonger l'histoire d'un secteur urbain bigarré, longtemps chef-lieu de la vie nocturne et interlope de Montréal, tombé en déclin dans les années 1960 et pilonné dès lors de vastes chantiers 
institutionnels (Place des Arts, Complexe Desjardins, etc.). Or, voilà qu'au détour des années1980, plusieurs festivals montréalais, qui incarnent aujourd'hui l'identité «festive » de la ville, s'installent dans les espaces interstitiels du Faubourg St-Laurent. À L'ore des années 2000, on cherchera ainsi à consolider la fonction spectaculaire de l'est du centre-ville par l'entremise d'un projet d'urbanisme, ledit "Quartier des spectacles", permettant de reconnecter les éléments disjoints du secteur et d'imposer au quartier cette ambiance festive qui était devenu sa marque distinctive. Depuis, plan lumière, pavés thématiques, places hybrides servant autant festivaliers et utilisateurs au quotidien, ainsi que l'ajout ou la rénovation de divers équipements culturels ont renforcé l'identité du secteur et promu les arts de la scène comme carte de visite de Montréal. Or, comme le signale Simon Harel, l'un des codirecteurs de l'ouvrage, ce traitement « horizontal» de l'espace urbain, oscillant entre table rase du passé et référencement à une époque révolue, continue de soulever diverses controverses - évoquées dans le livre - que le bruit de l'hyperfestivalité n'a pas été en mesure d'enterrer à ce jour.

Le chapitre de Joël Thibert, placé en liminaire d'une série de réflexions sur la symbolique des lieux, nous signale d'emblée que l'entité «Quartier des spectacles» n'est pas une production anonyme sortie des cartons de quelque fonctionnaires obscurs, mais bien le fruit d'un travail collectif de conception qui passera de mains en mains au cours de sa jeune histoire. Proposé par l'ADISQ au Sommet de Montréal de 2001, le projet de destination

culturelle autour de la Place des Arts sera négocié dès le départ, voire contesté par de nombreux acteurs institutionnels, de sorte que la désignation courante de Quartier des spectacles recouvre en fait plusieurs réalités. De sa mouture originale naitra en effet le Partenariat du Quartier des spectacles, l'entité responsable notamment de la communication de la marque du secteur, à ne pas confondre avec le projet urbanistique commandé par la ville à la société Quartier International de Montréal et conçu par la firme Daoust Lestage. Le travail de Thibert, s'inscrivant dans la lignée d'une sociologie de l'architecture, propose une lecture de l'évolution du projet depuis l'intérieur (l'auteur, urbaniste, a intégré l'équipe de la Société QMI en 2008). Deux constats importants se dégagent de cette expérience de première main: on y voit d'abord un projet qui a été négocié plus qu'imposé, et sur lequel aucun groupe d'intervenants n'a eu la maitrise complète, ce qui explique par ailleurs son caractère perpétuellement inachevé. On réitère également une donnée fondamentale concernant la vision des concepteurs du projet, à savoir leur souci d'inscrire le Quartier de spectacles dans l'imaginaire des lieux, non pas dans une logique de remplacement, mais bien de filiation avec la vocation culturelle du secteur. C'est ainsi, par exemple, que le parcours lumières du Quartier des spectacles, une conception originale de Ruedi Baur et Jean Beaudoin, évoque le Red Light District d'autrefois par l'emploi de points rouges signalant, sur les pavés, les lieux de diffusion culturelle.

5 C'est d'ailleurs sur le terrain de l'imaginaire du lieu que les chapitres de Jonathan Cha et Eleonora Diamanti, ainsi que celui de Robert Schwartzwald, nous amènent par la suite. Les premiers critiquent la filiation mnémonique suggérée par le Quartier des spectacles sous l'angle d'une opposition entre la « culture établie » mise de l'avant par les nouvelles interventions aseptisées, et la «contre-culture » d'autrefois incarné par des lieux culturels rasés (le Spectrum) ou occultés (le Café Cléopâtre). Dans une étude des représentations littéraires du secteur avant les années 1950, Schwartzwald nous montre quant à lui que le désordre et l'hétérogénéité du secteur en constituaient des valeurs 
positives, et qu'entre « spectacle et Spectacle, quartier et Quartier» (p. 74), les nouvelles logiques d'esthétisation s'inscrivent en continuité avec les opérations de nettoyage qui sévissent dans le secteur depuis les années 1060 .

6 Les chapitres de Josiane Poirier et de Claire Néron-Déjean nous rappellent quant à eux à une réalité quasi occultée lorsqu'il est question du Quartier des spectacles, à savoir qu'il s'agit avant tout, comme l'indique son nom, d'un «quartier », ce qui implique que des résidents y vivent et que des artistes y travaillent. C'est la nuit que la mixité fonctionnelle du secteur est le plus mise à mal selon Néron-Déjean. Tandis que les débordements de la vie festive augmentent inéluctablement, c'est la ville qui dort qui en subit les conséquences. Il est en ce sens dangereux de penser les « lieux d'attractivité » comme des non-lieux pour les 7000 résidents qui habitent le secteur, et d'oublier leurs besoins en «zones de rupture " les coupant du bruit des foules. La situation précaire des artistes dans le secteur est quant à elle hautement paradoxale, nous dit Josiane Poirier, si l'on songe au rôle dévolu à la culture dans la stratégie de régénération urbaine adoptée ici. Qu'on ait démoli les premiers centres d'artistes autogérés de Montréal sis dans l'édifice Blumenthal pour construire, à la place, de nouveaux équipements dédiés à la culture, illustre par l'absurde l'instrumentalisation des artistes dans ce type de stratégie urbaine ; forcés d'aller travailler ailleurs en ville (dans des locaux aux loyers plus abordables), ils sont refoulés, de surcroit, aux accès institutionnels de la programmation culturelle du site. Ainsi, la prétention de constituer une «vitrine sur la culture » demeure peut-être l'aspect le plus déficient du Quartier des spectacles à ce jour. Nik Luca et coll., dans leur chapitre, proposent en ce sens que le Quartier des spectacles s'oriente vers d'autres devenirs possibles, et se mute en un véritable espace d'expérimentation, plus "carnavalesque " dans l'articulation entre spectateurs et acteurs, et ouvert à des manifestations artistiques informelles. Ouvert, au fond, à un niveau d'indétermination qui en ferait un véritable lieu de culture.

7 Dans un chapitre fort éclairant, Thomas-Bernard Kenniff pose son regard - et son appareil photo - sur le «potentiel d'inaccomplissement du Quartier des spectacles» (p. 121), jugeant par-là que c'est l'ambivalence fondamentale du projet qui permet le dialogue avec un territoire hétérogène sur le plan sociospatial. Envisageant le Quartier des spectacles à la manière d'un « chronotope » (Bakhtine), soit comme une tentative de stabiliser une identité urbaine dans le temps, Kenniff met en lumière les ambigüités de cette production spatiale qui ne coïncide pas parfaitement avec son territoire. Entre ses mailles apparaissent en effet des interstices non investis spectaculairement où surgissent des pratiques spatiales et temporelles alternatives (skate, itinérance, quotidienneté, etc.). Or, c'est bien la "porosité spatiale du Quartier des spectacles » qui en constitue un des " plus grands atouts » (p. 153), car si cette production spatiale collective trace des lignes de démarcation entre des aspirations contraires, elle demeure, à ce jour, potentiellement ouverte à d'autres urbanités en devenir. C'est peut-être aussi à travers cet éclectisme que le Quartier des spectacles se distingue parmi les stratégies de régénération culturelle observées dans d'autres métropoles, car comme le rappellent Lukas et coll., le projet montréalais fait figure d'exception par la grande diversité d'acteurs qui y prennent part, et par le caractère public et non contrôlé de ses sites.

8 Le piège qu'évite l'ouvrage, dans son ensemble, c'est d'adopter une ligne dure énonçant l'incompatibilité fondamentale et irréversible entre l'imaginaire d'un site, son illustre histoire autant que ses usages sociaux marginalisés, et tout travail de requalification d'un secteur dont les interventions ne pourraient que distiller la vraie nature, une fois et pour 
toutes. "A house is not a home » dit l'expression, et les outils des bâtisseurs de ville, tout aussi sophistiqués qu'ils soient devenus aujourd'hui, n'ont pas été conçus pour construire un imaginaire urbain. Cette dislocation, une fois comprise et acceptée, s'avère même être une force, un atout. La rencontre entre le projet urbain (le Quartier des spectacles) et son territoire (le Faubourg St-Laurent, mais aussi, par métonymie, Montréal tout entier) est bel et bien pensée de manière critique dans les différents chapitres du livre, mais on reconnait d'une part qu'il y a négociation entre les deux réalités plutôt que simple rejet mutuel. D'autre part, le Quartier des spectacles est pensé ici comme un projet complexe, peut-être plus hétérogène qu'homogène finalement, et qui est en outre toujours en chantier, notamment dans son extension vers l'est autour du pôle Quartier latin. En somme, reconnait Laurent Lussier dans la conclusion de l'ouvrage, c'est bel et bien la tentative d'unifier un secteur urbain désarticulé depuis des décennies qui est à l'origine des riches débats qu'il suscite depuis, rappelant en ce sens qu'il faut reconnaitre à ses instigateurs le mérite d'avoir révélé « l'irréductible diversité de ce quartier » (p.213).

\section{BIBLIOGRAPHIE}

Kalandides, Ares, Kavaratzis, Mihalis, Lucarelli, Andrea, \& Olof Berg, Per. (2011). City Branding : A State-of-the-art Review of the Research Domain. Journal of place management and development, 4(1), 9-27. 